\title{
ORIGIN OF MONACOLIN L FROM ASPERGILLUS TERREUS CULTURES
}

\author{
L. R. TReiber and R. A. ReAmer \\ Merck Sharp \& Dohme Research Laboratories, \\ Rahway, NJ 07065, U.S.A. \\ C. S. RooneY and H. G. Ramit \\ Merck Sharp \& Dohme Research Laboratories, \\ West Point, PA 19486, U.S.A.
}

(Received for publication May 9, 1988)

\begin{abstract}
In freshly harvested Aspergillus terreus cultures grown for the production of lovastatin (formerly called mevinolin), no monacolin $\mathrm{L}$ could be detected. However, during the isolation of lovastatin, significant quantities of monacolin $\mathrm{L}$ appeared. It has been discovered that a new metabolite structurally related to the members of the monacolin series is present. This metabolite is unstable and under mildly acidic conditions and elevated temperature, it converts to monacolin $\mathrm{L}$. The subject metabolite is proven to be a hydroxylated derivative of dihydromonacolin $\mathrm{L}$ identified as $3 \alpha$-hydroxy-3,5-dihydromonacolin $\mathrm{L}$. It seems that all monacolin $L$ found later during various treatments of the broth and broth extracts is formed from that precursor via a dehydration reaction. The new metabolite was converted to its phenacyl ester, by means of extractive alkylation, for isolation and structure elucidation by chemical, chromatographic and spectroscopic methods. This ester, on standing, gradually formed the corresponding lactone.
\end{abstract}

Compounds which inhibit cholesterol biosynthesis are potential drug candidates for the treatment of atherosclerosis and coronary heart disease in humans. Such an effect is achieved by competitive inhibition of 3-hydroxy-3-methylglutaryl coenzyme A reductase, the key enzyme in the pathway of cholesterol biosynthesis. Potent inhibitors such as compactin (ML-236B) ${ }^{1)}$, dihydrocompactin ${ }^{2)}$, lovastatin ${ }^{3,4)}$, and several other compounds of the monacolin series ${ }^{5 \sim 7)}$ were found among the metabolites of certain fungi including Monascus ruber, Penicillium citrinum and Aspergillus terreus. The theoretical and practical importance of these compounds is evidenced by studies directed at their biosynthesis $^{8-10)}$ and metabolism ${ }^{11,12}$.

$A$. terreus was described as the culture of choice for the production of lovastatin ${ }^{13)}$. Intermediate products during isolation, particularly crude samples immediately after lactonization contain significant amounts of monacolin L. However, no detectable amounts of same are found in freshly harvested broths. The observations presented here provide an explanation for this phenomenon.

\section{Materials and Methods}

Fermentation of $A$. terreus $^{18)}$

Tubes of lyophilized culture MF-4845 were suspended each in $10 \mathrm{ml}$ of sterilized medium consisting of the following nutrients: Corn steep liquor $5 \mathrm{~g}$, tomato paste $40 \mathrm{~g}$, oatmeal $10 \mathrm{~g}$, glucose $10 \mathrm{~g}$ and trace element solution $10 \mathrm{~g}$ in 1 liter of tap water and adjusted to $\mathrm{pH}$ 6.8. The trace element solution contained $\mathrm{FeSO}_{4} \cdot 7 \mathrm{H}_{2} \mathrm{O} 1,000 \mathrm{mg}, \mathrm{MnSO}_{4} \cdot 4 \mathrm{H}_{2} \mathrm{O} 1,000 \mathrm{mg}, \mathrm{CuCl}_{2} \cdot 2 \mathrm{H}_{2} \mathrm{O} 25 \mathrm{mg}, \mathrm{CaCl}_{2} \cdot 2 \mathrm{H}_{2} \mathrm{O} 100 \mathrm{mg}$, $\mathrm{H}_{3} \mathrm{BO}_{3} 56 \mathrm{mg},\left(\mathrm{NH}_{4}\right)_{6} \mathrm{Mo}_{7} \mathrm{O}_{24} \cdot 4 \mathrm{H}_{2} \mathrm{O} 19 \mathrm{mg}$ and $\mathrm{ZnSO}_{4} \cdot 7 \mathrm{H}_{2} \mathrm{O} 200 \mathrm{mg}$ in 1 liter of tap water. The inoculated samples were incubated in an unbaffled $250-\mathrm{ml}$ Erlenmeyer flask for 24 hours at $28^{\circ} \mathrm{C}$ on 
a $220 \mathrm{rpm}$ shaker ( $5 \mathrm{~cm}$ throw). Two unbaffled 2-liter Erlenmeyer flasks containing $500 \mathrm{ml}$ of the medium were then inoculated each with $10 \mathrm{ml}$ of the first stage fermentation growth from the seed mixture. These too were shaken 24 hours at $28^{\circ} \mathrm{C}$. One liter of the second stage fermentation broth was then added to 485 liters of the sterilized medium containing Cerelose ( $45 \mathrm{~g} / \mathrm{liter}$ ), peptonized milk ( $25 \mathrm{~g} /$ liter), autolyzed yeast $(2.5 \mathrm{~g} /$ liter $)$ and polyglycol $\mathrm{P} 2000(2.5 \mathrm{~g} /$ liter $)$ at $\mathrm{pH} 7.0$ in a 750 -liter stainless steel fermentation vat. The mixture was incubated at $85 \mathrm{rpm}$ for 12 hours then $130 \mathrm{rpm}$ for 84 hours at $28^{\circ} \mathrm{C}$ with an air flow of 160 liter/minute for 12 hours then 320 liter/minute for 84 hours.

Separation of $3 \alpha$-Hydroxy-3,5-dihydromonacolin $L$ (1a) from Fermentation Broth

The $\mathrm{pH}$ of the above fermentation broth was adjusted to 5.0. The supernatant was separated from the mycelia by means of centrifugation. A 2-liter portion of the clear liquid was passed through a column (i.d.: $2.7 \mathrm{~cm}$, height: $39 \mathrm{~cm}, 225 \mathrm{ml}$ ) containing Diaion HP-20 resin packed with water. The loaded column was washed first with water then with $1 \mathrm{~N} \mathrm{NH}_{4} \mathrm{OH}(500 \mathrm{ml}$ each). The elution of the column was performed with a mixture of acetonitrile - water $(2: 3,500 \mathrm{ml})$. The eluate contained $102 \mathrm{mg}$ of $1 \mathrm{a}$.

\section{Isolation of $3 \alpha$-Hydroxy-3,5-dihydromonacolin L Phenacyl Ester (1b)}

Extractive Alkylation ${ }^{14,15)}$ : The supernatant of the above fermentation broth was isolated from the mycelia by means of centrifugation. A 1 -liter portion of the clear liquid was acidified with $85 \%$ $\mathrm{H}_{3} \mathrm{PO}_{4}$ to $\mathrm{pH} 4.0$ and extracted with $350 \mathrm{ml}$ of methylene chloride. The aqueous phase was brought to $\mathrm{pH} 6.2$ with $50 \% \mathrm{NaOH}$ solution then mixed with $17 \mathrm{ml}$ of $50 \% \mathrm{NaOH}$ solution, $17 \mathrm{ml}$ of $85 \%$ $\mathrm{H}_{3} \mathrm{PO}_{4}$ and $250 \mathrm{ml}$ of $1.0 \mathrm{M}$ tetrabutylammonium dihydrogen phosphate solution. The $\mathrm{pH}$ was adjusted to 6.2. The homogeneous aqueous solution was agitated with $500 \mathrm{ml}$ of methylene chloride containing $3.5 \mathrm{~g}(17.7 \mathrm{mmol})$ of 2-bromoacetophenone at room temperature for 3 hours. The phases were separated. The organic phase was dried over anhydrous $\mathrm{Na}_{2} \mathrm{SO}_{4}$ and filtered.

First Chromatography: The methylene chloride solution containing $c a .230 \mathrm{mg}$ of product, obtained in the previous step was charged onto the column (i.d.: $3.5 \mathrm{~cm}$, height: $21 \mathrm{~cm}, 200 \mathrm{ml}$ ) containing silica gel (mesh 60 200) packed with methylene chloride. The development of the chromatogram was performed in a stepwise gradient fashion starting with methylene chloride and proceeding with methylene chloride - EtOAc $(9: 1,4: 1,7: 3,3: 2$, and $1: 1,200 \mathrm{ml}$ of each). The bulk of the target compound was eluted in the range of methylene chloride - EtOAc $(7: 3$ through $3: 2)$. The main fractions were combined and evaporated to a dry residue $(224 \mathrm{mg})$.

Second Chromatography: One half of the dry residue obtained above was dissolved in a small amount of acetonitrile and loaded onto a column (i.d.: $1.5 \mathrm{~cm}$, height: $40 \mathrm{~cm}, 70 \mathrm{ml}$ ) containing Diaion HP-20 resin packed with water. The chromatogram was developed in a stepwise gradient fashion with $100 \mathrm{ml}$ of each of the following eluents; water, water - acetonitrile $(9: 1,4: 1,7: 3,3: 2,1: 1$, $2: 3$, and $3: 7)$. The target compound was eluted in the mixture, water - acetonitrile $(2: 3)$. The main fractions were combined and evaporated to dryness $(85 \mathrm{mg})$.

Third Chromatography: The final purification step of the above product was carried out on silica gel (mesh $60 \sim 200$ ) again. The dry residue of the previous step was dissolved in a small volume of methylene chloride and charged onto a silica gel column (i.d.: $1.5 \mathrm{~cm}$, height: $30 \mathrm{~cm}, 53 \mathrm{ml}$ ) packed with hexane. For the stepwise-gradient elution, $50 \mathrm{ml}$ of each of the following solvent mixtures were used; hexane-EtOAc $(4: 1,3: 2,1: 1,2: 3,3: 7$, and 1:4) and EtOAc. The elution of the pure product began with the solvent composition hexane - EtOAc $(1: 4)$ and was completed with EtOAc. The main fractions were combined and evaporated to dryness. The viscous, oily product $1 \mathrm{~b}(52.6 \mathrm{mg})$ was used for the structure elucidation studies.

\section{Isolation of Lactone 2 from $1 \mathbf{b}$}

A sample of $1 b(54 \mathrm{mg})$, which had been allowed to stand for several months, was subjected to fiash chromatography on a $17-\mathrm{mm}$ (O.D.) column containing $18 \mathrm{~cm}$ of $230 \sim 400$ mesh silica gel. Development was begun with $40 \%$ EtOAc - hexane. The EtOAc content was increased stepwise to the 60,80 , and $100 \%$ levels. Fractions were combined based on TLC. Three components were separated: $1 \mathrm{~b}(20 \mathrm{mg}), 2(11 \mathrm{mg})$, and 2-hydroxyacetophenone $(5 \mathrm{mg})$. 


\section{Analytical Procedures}

TLC: Standard $20 \times 20 \mathrm{~cm}$ analytical precoated TLC plates of type Silica gel $60 \mathrm{~F}_{254}$ (E. Merck) were used. The chromatograms were developed in EtOAc in the ascending mode. The phenacyl ester derivative 1b was located under the UV light as a dark spot on fluorescing background with an $\mathrm{Rf}$ value of 0.30 . For the detection of 2 , a $7 \%$ ethanol solution of phosphomolybdic acid was utilized. The Rf value was determined to be 0.15 . TLC was used for monitoring extractive alkylation and chromatographic purification of the products.

HPLC: Modular HPLC instrumentation consisting of the Altex model 421 gradient system and Hewlett-Packard model 1040A detection system was used. The HPLC traces at $238 \mathrm{~nm}$ and the UV spectra of the predominant fractions were stored on computer discs for evaluation. The separations were performed on a LiChrosorb RP-8 150-3 CGC (E. Merck) column in gradient elution mode. Two binary gradient programs were used both at ambient temperature at a flow rate of $0.7 \mathrm{ml} / \mathrm{minute}$. The solvent components were A; $0.01 \mathrm{M}$ phosphoric acid in water, and B; acetonitrile. The gradient programs were as follows:

Gradient I: $\quad 0 \sim 15$ minutes: Solvent $\mathrm{B}$ in $\mathrm{A}+\mathrm{B}: 50 \%$, constant, $15 \sim 17$ minutes: Solvent B in A+B: $50 \sim>100 \%$, linear gradient, $17 \sim 30$ minutes: Solvent B in $\mathrm{A}+\mathrm{B}: 100 \%$, constant.

The retention times of the fractions of interest in this gradient were as follows: Monacolin $L$ hydroxy acid (3a) and lactone (4); 5.2 and 9.5 minutes, respectively, lovastatin hydroxy acid and lactone; 6.6 and 12.2 minutes, respectively.

Gradient II: $\quad 0 \sim 2$ minutes: Solvent B in A+B: $40 \%$, constant,

$2 \sim 10$ minutes: Solvent B in $A+B: 40 \sim>50 \%$, linear gradient, $10 \sim 20$ minutes: Solvent $B$ in $A+B: 50 \sim>100 \%$, linear gradient, 20 30 minutes: Solvent B in A+B: $100 \%$, constant.

The retention times of the phenacyl esters of $3 \alpha$-hydroxy-3,5-dihydromonacolin $\mathrm{L}(\mathbf{1 b})$ and monacolin $\mathrm{L}(3 \mathrm{~b})$ were 5.9 and 19.0 minutes, respectively.

Detection Based on Chemical Characteristics: The procedure for monitoring $3 \alpha$-hydroxy-3,5dihydromonacolin L (1a) was as follows: Aliquots of untreated samples were first assayed by HPLC at a detector setting of $238 \mathrm{~nm}$ to establish a baseline. Then, identical aliquots were acidified with phosphoric acid to $\mathrm{pH} 2 \sim 3$ and agitated with toluene at $70^{\circ} \mathrm{C}$ for $c a .2$ hours. The phases were separated. Toluene was displaced with acetonitrile as solvent for LC assay. The presence of monacolin $\mathrm{L}$ in the toluene phase indicated the presence of its chemical precursor in the original sample. Similarly, $\mathbf{1 b}$ was found through its conversion to the phenacyl ester of monacolin $\mathrm{L}(\mathbf{3 b})$.

Mass Spectrometry: Field desorption (FD) and fast atom bombardment (FAB) mass spectral analyses were performed on the VG-MMZAB-HF mass spectrometer operating at a dynamic resolution of $1,000 \mathrm{ppm}$. Thermospray (TSP) analyses were performed on the Nermag-1010 quadruple mass spectrometer incorporating the vestal TSP interface.

For FD analysis, the source parameters of the mass spectrometer were optimized in field ionization mode (FI) using acetone as the test compound. About $0.2 \mu 1$ of analate (10\% EtOAc solution) was deposited onto the activated FI/FD emitter, which was then introduced into the ion source and desorbed with an applied emitter current of $30 \mathrm{~mA}$. In the case of FAB analysis, about $0.4 \mu 1$ of solution was added to a glycerol matrix, introduced into the ion source of the mass spectrometer and bombarded with $10 \mathrm{keV}$ argon atoms. Mass spectra in both experiments were acquired at a scan rate of 15 seconds/decade of mass, by way of the on-line VG-11/250 data system.

TSP analyses were performed by the method of direct injection - i.e., no column was used for component separation. One $\mu 1$ of the $10 \%$ EtOAc solution was injected into the mobile phase consisting of aqueous ammonium acetate $(0.1 \%)$ - acetonitrile $(9: 1)$ at a flow rate of $1 \mathrm{ml} / \mathrm{minute}$. The vaporizer tip of the TSP interface was maintained at $220^{\circ} \mathrm{C}$ and the source block temperature of the mass spectrometer was optimized at $300^{\circ} \mathrm{C}$. Mass spectral data were acquired into the SIDAR data system at a scan rate of 80 daltons/second.

NMR Spectroscopy: ${ }^{1} \mathrm{H}$ and ${ }^{13} \mathrm{C}$ NMR studies, using two-dimensional (2D) NMR, homonuclear double-resonance and nuclear Overhauser effect (NOE) difference spectroscopy, were used to determine 
spin-spin coupling pathways, determine stereochemistry and to make chemical shift assignments in 1b. Spectra were obtained in $\mathrm{CD}_{3} \mathrm{CN}$ and $\mathrm{CDCl}_{3}$ and were run on Bruker AM-300 and WM-250 NMR spectrometers. ${ }^{1} \mathrm{H}$ NMR spectra of 2 were determined on a Varian XL-300 spectrometer in $\mathrm{CD}_{3} \mathrm{CN}$.

\section{Results and Discussion}

The search for a new chemical entity was prompted by the observation that while processed samples derived from broths of $A$. terreus for the production of lovastatin (previously known as mevinolin) consistently contain significant amounts of monacolin L (3a and 4), direct assays of freshly harvested cultures indicated no detectable amounts of the same. As the first step in the search for the origin of monacolin $\mathrm{L}$, methylene chloride is used for the extraction of nonpolar components including acids at $\mathrm{pH}$ 4. Methylene chloride is displaced with toluene to carry out the lactonization at elevated temperature. Lovastatin is found in this fraction. At the end of lactonization, traces of monacolin $\mathrm{L}$ are also detected. None of the LC fractions in the broth pre-extracted with methylene chloride at pH 4 show the UV spectrum characteristic of the conjugated double bonds of the fused ring system. The bulk of monacolin $\mathrm{L}$ is recovered in the toluene phase initially as hydroxy acid (3a) as well as lactone (4) as a result of a mild extraction with toluene (at pH $2 \sim 3$ and $70^{\circ} \mathrm{C}$ ) of the pre-extracted broth. This observation indicates that the formation of the nonpolar monacolin $\mathrm{L}$ is a result of a chemical reaction from a polar precursor, or as this study specifically demonstrates, from 1a. Prolonged treatment eventually converts monacolin L (3a) completely to its lactone form (4).

The isolation and purification of free 1a is seriously hampered by the fact that it is very unstable. In addition, its direct monitoring during the early phase of isolation is practically impossible due to its weak UV absorbance relative to other contaminants present. A suitable derivatization helps to alleviate these problems. The presence of the free carboxyl group in the hydroxy acid form (1a) offers a suitable site for derivatization. Under the conditions of extractive alkylation ${ }^{14,15)}$ (neutral $\mathrm{pH}$, ambient temperature) the rest of the molecule remains intact. The resulting phenacyloxy derivative (1b) exhibits characteristic UV spectra, hence it becomes readily detectable. Once the correlation between a fraction disappearing from the LC recording (retention time 5.9 minutes) upon treatment at elevated temperature in mild acid and the emerging $\mathbf{3 b}$ peak (19.0 minutes) is established, the analytical monitoring of isolation steps becomes trivial. The fraction in question is then chromatographically purified for structure elucidation. The conversion pattern is verified by means of similar treatment of purified $\mathbf{1 b}$ and identifying the

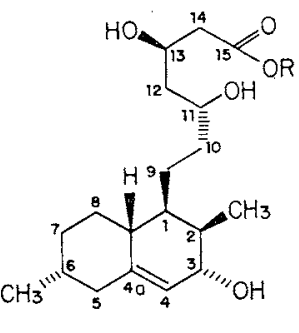

1<smiles>C[C@H]1CC[C@H]2C(=C[C@H](O)[C@@H](C)[C@@H]2CC[C@H]2C[C@H](O)CC(=O)O2)C1</smiles>

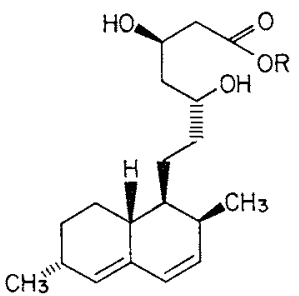

3

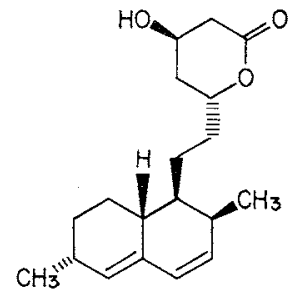

4

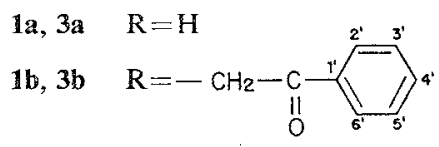


resulting product as $3 \mathrm{~b}$. Based on the above observations, it is concluded that $3 \mathrm{a}$ and $\mathbf{4}$ are formed from 1a only as an artefact of isolation rather than (in its open acid form) as a discrete product of biosynthesis in the $A$. terreus cultures of this investigation.

In support of structure 1a, FAB-MS derived from the initial isolate obtained from fermentation broth, gave two key mass peaks at $m / z 341$ and 363, which were attributed to the pseudomolecular ions $(\mathrm{M}+\mathbf{H})^{+}$and $(\mathrm{M}+\mathrm{Na})^{+}$of 1a. The mass peaks at $\mathrm{m} / \mathrm{z} 323,305$ and 287 were rationalized as $(\mathrm{M}+\mathrm{H})^{+},\left(\mathrm{M}-\mathrm{H}_{2} \mathrm{O}+\mathrm{H}\right)^{+}$and $\left(\mathrm{M}-2 \mathrm{H}_{2} \mathrm{O}+\mathrm{H}\right)^{+}$for lactone 2. These results were similar to those observed by TSP-MS, as illustrated in Table 1.

The phenacyl ester derivative $\mathbf{1 b}$ on standing over a period of time is converted slowly to the corresponding lactone 2 . The latter, which was purified by flash chromatography on silica gel, was identified based on characteristic chemical shift changes for the two protons on the non-carbonyl oxygen bearing carbons of the lactone moiety. Conclusive evidence for the molecular weight of 2 was established from the FD-MS, which exhibits a well defined molecular ion at $\mathrm{m} / \mathrm{z} 322$ and other characteristic mass peaks at $m / z 305(\mathrm{M}-\mathrm{OH})^{+}, 304\left(\mathrm{M}-\mathrm{H}_{2} \mathrm{O}\right)^{+}$and $287\left(\mathrm{M}-\mathrm{OH}-\mathrm{H}_{2} \mathrm{O}\right)^{+}$, illustrated in the mass spectrum (Fig. 1).

Table 1, FAB and TSP-MS results, of initial isolate from MK-803 fermentation broth.

\begin{tabular}{llll}
\hline \multirow{2}{*}{ Compound type } & & \multicolumn{2}{c}{$m / z$ (relative intensity \%) } \\
\cline { 3 - 4 } & & FAB-MS & TSP-MS \\
\hline $3 \alpha$-Hydroxy-3,5-dihydromonacolin L (acid) (1a) & $\mathrm{M}+\mathrm{H}$ & $341(12)$ & $341(17)$ \\
& $\mathrm{M}+\mathrm{Na}$ & $363(18)$ & - \\
$3 \alpha$-Hydroxy-3,5-dihydromonacolin L (lactone) (2) & $\mathrm{M}+\mathrm{H}$ & $323(30)$ & $323(63)$ \\
& $\mathrm{M}-\mathrm{H}_{2} \mathrm{O}+\mathrm{H}$ & $305(35)$ & $305(65)$ \\
& $\mathrm{M}-2 \mathrm{H}_{2} \mathrm{O}+\mathrm{H}$ & $287(57)$ & $287(100)$ \\
\hline
\end{tabular}

Relative intensity values in parentheses. Mass to charge ratio $(\mathrm{m} / \mathrm{z})$ values in daltons.

Fig. 1. FD-MS of compound 2.

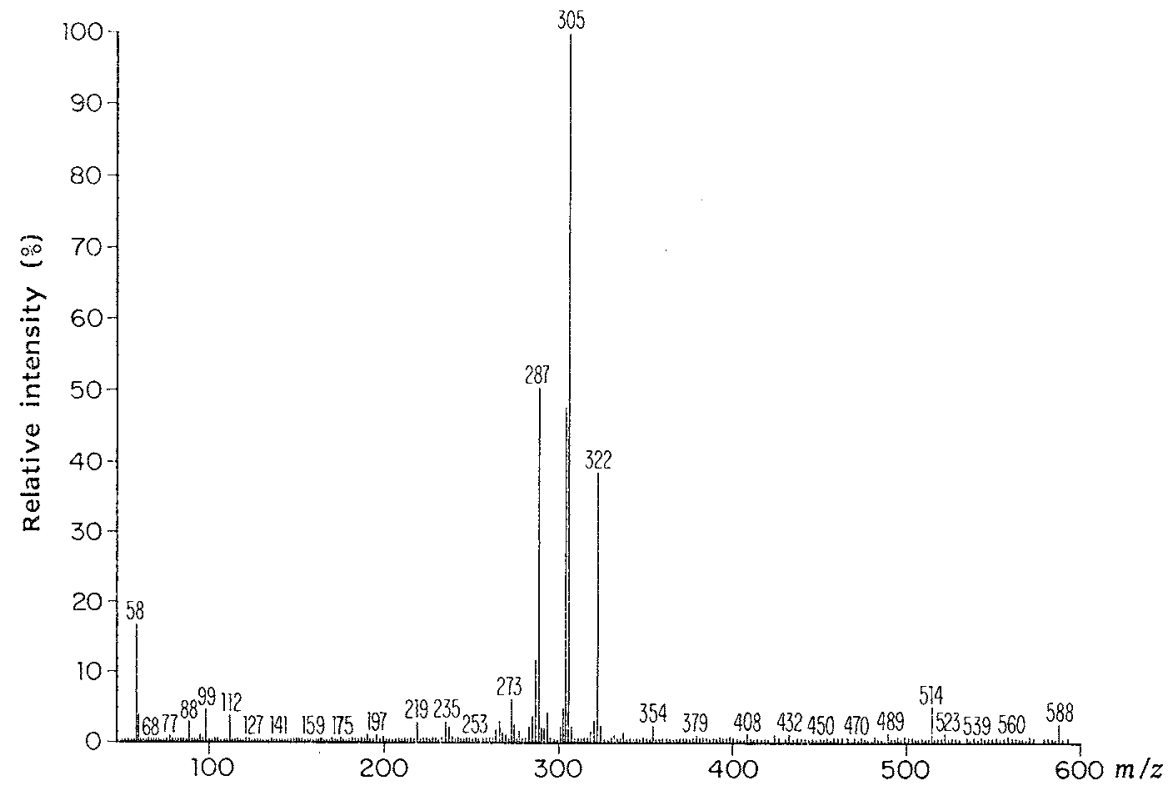


Table 2. ${ }^{1}$ H NMR data of $\mathbf{1 b}$.

\begin{tabular}{ll}
\hline \multicolumn{1}{c}{ Proton } & \multicolumn{1}{c}{$\begin{array}{c}\text { Assignment } \\
\text { (ppm, } J \text { in } \mathrm{Hz})\end{array}$} \\
\hline $2^{\prime}, 6^{\prime}-\mathrm{H}$ & $7.94(\mathrm{~m})$ \\
$4^{\prime}-\mathrm{H}$ & $7.67(\mathrm{~m})$ \\
$3^{\prime}, 5^{\prime}-\mathrm{H}$ & $7.53(\mathrm{~m})$ \\
$\mathrm{OCH}_{2}$ & $5.43,5.38$ \\
& $\left(\mathrm{AB}\right.$ quartet, $\left.{ }^{2} J=16.8\right)$ \\
$4-\mathrm{H}$ & $5.35(\mathrm{br} \mathrm{dd}, J=4.3,2.0)$ \\
$13-\mathrm{H}$ & $4.23(\mathrm{~m})$ \\
$13-\mathrm{OH}$ & $3.92(\mathrm{~d}, J=3.5)$ \\
$11-\mathrm{H}$ & $3.75(\mathrm{~m})$ \\
$3-\mathrm{H}$ & $3.66(\mathrm{~m})$ \\
$11-\mathrm{OH}$ & $3.28(\mathrm{~d}, J=3.9)$ \\
$14-\mathrm{H}_{2}$ & $2.6(\mathrm{~m})$ \\
$3-\mathrm{OH}_{8}-\mathrm{H}_{2}, 7-\mathrm{H}_{2}, 6-\mathrm{H}$, & $2.54(\mathrm{~d}, J=6.3)$ \\
$5-\mathrm{H}_{2}, 2-\mathrm{H}, 1-\mathrm{H}$, & \\
$8 \mathrm{a}-\mathrm{H}, 9-\mathrm{H}_{2}, 10-\mathrm{H}_{2}$, & Overlapping multiplets \\
$12-\mathrm{H}_{2}$ & $2.3 \sim 1.1$ \\
$6-\mathrm{CH}_{3}$ & \\
$2-\mathrm{CH}_{3}$ & $0.87(\mathrm{~d}, J=7.0)$ \\
\hline
\end{tabular}

${ }^{1} \mathrm{H}$ spectrum was run in $\mathrm{CD}_{3} \mathrm{CN}$ at $250.13 \mathrm{MHz}$ and referenced to the residual $\mathrm{CHD}_{2} \mathrm{CN}(1.93$ ppm).

Table 3. ${ }^{19} \mathrm{C}$ NMR data of $\mathbf{1 b}$.

\begin{tabular}{cc|cc}
\hline Carbon & $\begin{array}{c}\text { Assignment } \\
(\text { ppm) }\end{array}$ & Carbon & $\begin{array}{c}\text { Assignment } \\
(\mathrm{ppm})\end{array}$ \\
\hline $1^{\prime}-\mathrm{CO}$ & 194.2 & 14 & 43.2 \\
15 & 172.0 & 5 & 42.1 \\
$4 \mathrm{a}$ & 141.8 & $8 \mathrm{a}$ & 41.7 \\
$1^{\prime}$ & 135.2 & 2 & 40.5 \\
$4^{\prime}$ & 135.0 & 1 & 37.1 \\
$2^{\prime}, 6^{\prime} ; 3^{\prime}, 5^{\prime}$ & 129.9, & 10 & 36.7 \\
& 128.8 & 7 & 32.5 \\
4 & 123.5 & 6 & 29.9 \\
11 & 71.9 & 8 & 28.1 \\
3 & 71.0 & 9 & 25.4 \\
13 & 69.2 & $6-\mathrm{CH}_{3}$ & 17.8 \\
$\mathrm{OCH}_{2}$ & 67.3 & $2-\mathrm{CH}_{3}$ & 12.7 \\
12 & 43.9 & & \\
\hline
\end{tabular}

${ }^{13} \mathrm{C}$ spectrum was run in $\mathrm{CD}_{3} \mathrm{CN}$ at $62.9 \mathrm{MHz}$ and referenced to the $\mathrm{CD}_{3}$ group of the solvent (1.3 ppm).

Unlike the phenacyl ester $\mathbf{1 b}$, the chromatographically purified lactone 2 gave a negative ion-like FAB-MS with a mass peak at $\mathrm{m} / \mathrm{z} 321$ $(\mathrm{M}-\mathrm{H})^{+}$in the molecular ion region. However, since the other mass peaks in the spectrum at $m / z 345,305$ and 287 can be attributed to the $(\mathrm{M}+\mathrm{Na})^{+}$, $\left(\mathrm{M}-\mathrm{H}_{2} \mathrm{O}+\mathrm{H}\right)^{+}$and $\left(\mathrm{M}-2 \mathrm{H}_{2} \mathrm{O}+\mathrm{H}\right)^{+}$, it is postulated that the molecule undergoes $\mathrm{H}_{2}$ elimination followed by protonation $\left(\mathrm{M}-\mathrm{H}_{2}+\mathrm{H}\right)^{+}$when analyzed by FAB-MS in a glycerol matrix. This neutral loss process is analogous to $\left(\mathrm{M}-\mathrm{H}_{2} \mathrm{O}+\mathrm{H}\right)^{+}$and $\left(\mathrm{M}-2 \mathrm{H}_{2} \mathrm{O}+\mathrm{H}\right)^{+}$observed for the acid as well as the lactone (Table 1).

${ }^{13} \mathrm{C}$ NMR of $\mathbf{1 b}$ shows the presence of a trisubstituted double bond and a third hydroxylated methine (supported by a new hydroxy resonance in the ${ }^{1} \mathbf{H}$ spectrum) besides those of the hydroxy ester side chain. The ${ }^{1} \mathrm{H}$ spin-spin coupling constant between the single olefinic hydrogen and this hydroxy bearing methine is $4.3 \mathrm{~Hz}$, indicative of a vicinal relationship. Since both methyls are $7 \mathrm{~Hz}$ doublets and therefore attached to methine carbons, the trisubstituted double bond must be at the ring junction. The structure consistent with this data is the 3-hydroxy 4-ene decalin system of $\mathbf{1 b}$.

The stereochemistry of the 3-hydroxy was established using NOE difference spectroscopy. Irradiation of the 2 -methyl shows a $6 \%$ enhancement to $3-\mathrm{CH}$ thus defining the stereochemistry of the hydroxy as $\alpha$.

${ }^{1} \mathrm{H}$ and ${ }^{13} \mathrm{C}$ NMR assignments for $\mathbf{1 b}$ are presented in Tables 2 and 3.

It is tempting to speculate that $\mathbf{1 a}$ may also be an intermediate on the fermentation path to lovastatin. Biosynthesis of 1 a from dihydromonacolin $\mathrm{L}^{4}$ could occur by hydroxylation at the 3-position of the octahydronaphthalene system with accompanying double bond rearrangement to the 4,4aposition. By comparison, the possible pathways for lovastatin biosynthesis from acetate postulated by VEDERAS and colleagues ${ }^{10)}$ suggest the 5-position as a probable location for a hydroxylated dihydromonacolin $\mathrm{L}$ intermediate. Work is continuing in our laboratories aimed at determining if 1a can indeed be converted to lovastatin under fermentation conditions. 
Acknowledgment

The authors are pleased to gratefully acknowledge the careful review work of Drs. A. W. DougLAS, Y. K. T. LAM, M. F. MALKIN and R. L. SMITH.

\section{References}

1) Endo, A.; M. Kuroda \& Y. Tsumta: ML-236A, ML-236B, and ML-236C, new inhibitors of cholesterogenesis produced by Penicillium citrinum. J. Antibiotics 29: 1346 1348, 1976

2) LaM, Y. K. T.; V.P. Gullo, R. T. Goggelman, D. Jorn, L. Huang, C. DeRiso, R. L. Monaghan \& I. PUtTer: Dihydrocompactin, a new potent inhibitor of 3-hydroxy-3-methylglutaryl coenzyme-A reductase from Penicillium citrinum. J. Antibiotics 34: 614 616, 1981

3) Endo, A.: Monacolin K, a new hypocholesterolemic agent produced by a Monascus species. J. Antibiotics 32: $852 \sim 854,1979$

4) ENDo, A.: Monacolin K, a new hypocholesterolemic agent that specifically inhibits 3-hydroxy-3-methylglutaryl coenzyme A reductase. J. Antibiotics 33: 334 336, 1980

5) Endo, A.; K. Hasumi, T. Nakamura, M. Kunishima \& M. Masuda: Dihydromonacolin L and monacolin X, new metabolites those inhibit cholesterol biosynthesis. J. Antibiotics 38: 321 327, 1985

6) Endo, A.; K. Hasum \& S. NeGishi: Monacolins J and L, new inhibitors of cholesterol biosynthesis produced by Monascus ruber. J. Antibiotics 38: 420 422, 1985

7) Endo, A.; D. Komagata \& H. Shimada: Monacolin M, a new inhibitor of cholesterol biosynthesis. J. Antibiotics 39: 1670 1673, 1986

8) Chan, J. K.; R. N. Moore, T. T. Nakashima \& J. C. Vederas: Biosynthesis of mevinolin. Spectral assignment by double-quantum coherence NMR after high carbon-13 incorporation. J. Am. Chem. Soc. 105: $3334 \sim 3336,1983$

9) Endo, A.; Y. Negishr, T. Iwashita, K. Mizukawa \& M. Hirama: Biosynthesis of ML-236B (compactin) and monacolin K. J. Antibiotics 38: 444 448, 1985

10) Moore, R. N.; G. Bigam, J. K. Chan, A. M. Hogg, T. T. Nakashima \& J. C. Vederas: Biosynthesis of the hypocholesterolemic agent mevinolin by Aspergillus terreus. Determination of the origin of carbon, hydrogen, and oxygen atoms by ${ }^{13} \mathrm{C}$ NMR and mass spectrometry. J. Am. Chem. Soc. 107: $3694 \sim 3701$, 1985

11) Serizawa, N.; K. Nakagawa, K. Hamano, Y. Tsuitia, A. Terahara \& H. Kuwano: Microbial hydroxylation of ML-236B (compactin) and monacolin K (MB-530B). J. Antibiotics 36: 604 607, 1983

12) Haruyama, H.; H. Kuwano, T. Kinoshita, A. Terahara, T. Nishigaki \& C. Tamura: Structure elucidation of the bioactive metabolites of ML-236B (mevastatin) isolated from dog urine. Chem. Pharm. Bull. 34: 1459 1467, 1986

13) Alberts, A. W.; J. Chen, G. Kuron, V. Hunt, J. Huff, C. Hoffman, J. Rothrock, M. Lopez, H. Joshua, E. Harris, A. Patchett, R. Monaghan, S. Currie, E. Stapley, G. Albers-Schonberg, O. Hensens, J. Hirshfield, K. Hoogsteen, J. Liesch \& J. Springer: Mevinolin: A highly potent competitive inhibitor of hydroxymethylglutaryl-coenzyme A reductase and a cholesterol-lowering agent. Proc. Natl. Acad. Sci. U.S.A. 77: $3957 \sim 3961,1980$

14) Brandstrom, A. \& U. JungGRen: Ion pair extraction in preparative organic chemistry. IV. Alkylation of methyl acetoacetate. Acta Chem. Scand. 23: 2204 2205, 1969

15) Furangen, A.: Extractive alkylation of organic acids. $X$. Kinetic studies on the alkylation of carboxylic acids with UV-absorbing alkylating agents. Acta Pharm. Suec. 22: 197 208, 1985 